\title{
PENSAR DEUS
}

Juvenal Savian Filho *

VASILIU, Anca. Penser Dieu - Noétique et métaphysique dans l'Antiquité Tardive. Paris: Vrin, 2018, 410p. ISBN 9782711628285.

A pensadora romeno-francesa Anca Vasiliu, pesquisadora do CNRS (Centre National de la Recherche Scientifique) e do Centro Léon-Robin (centro de pesquisas sobre o pensamento antigo da Université de Paris-Sorbonne) possui uma obra de altíssima e reconhecida relevância para os estudos do pensamento antigo e tardoantigo, não apenas por seu rigor técnico, filológico e conceitual, mas também pelas inspirações que por vezes se permite receber de temas contemporâneos que lançam luz sobre aspectos inusitados do pensamento antigo e tardoantigo ou mesmo encontram nessas formas de pensamento uma fonte sempre nova que, se não contribui para um esclarecimento total de tais temas, certamente possibilita expandir os horizontes de sua própria inteligibilidade. Tendo sido orientada por Jean-Luc Marion em seu doutorado sobre o conceito de diáfano no pensamento antigo e medieval, ${ }^{1}$ a pensadora é também historiadora da arte, especializada na arte bizantina e nas tradições culturais dos cristãos do Oriente.

Embora - lastimavelmente - nenhuma de suas obras tenha sido ainda traduzida em nosso país, Anca Vasiliu tem vínculos já bastante fortes

* Professor do Departamento de Filosofia da Nuniversidade Federal de São Paulo, - Unifesp. ${ }^{1}$ VASILIU, A. Du Diaphane - Image, milieu, lumière dans la pensée antique et médiévale. Paris: Vrin, 1997, 320 p., ISBN 9782711613410. 
com colegas e centros filosóficos brasileiros como a Unifesp, a UFMG e a UFRJ, sobretudo pelos minicursos e conferências já ministrados, além de ter recebido pesquisadores brasileiros na Universidade de Paris, e sobretudo oferecido preciosas colaborações em análises de projetos e pesquisas. Entre nós, ela é principalmente conhecida por seu trabalho de elucidar a real significação de Platão (junto, obviamente, de Aristóteles) nas formas de pensamento dos primeiros séculos da era cristã, contrariando a conhecida tese histórica - datada já dos anos 1970-1990 - segundo a qual os pensadores cristãos dos primeiros séculos não praticaram propriamente filosofia, mas apenas se serviram de elementos filosóficos antigos assim como alguém se serve de uma "caixa de ferramentas": na construção de certa inteligibilidade do discurso cristão, a filosofia antiga teria sido apenas instrumentalizada, e não cultivada nem desenvolvida. Anca Vasiliu, sobretudo em seus estudos sobre Gregório de Nazianzo, Gregório de Nissa e Basílio de Cesareia (mas não apenas!), tem demonstrado que os três grandes capadócios eram verdadeiramente platônicos em matéria filosófica, seguindo o filósofo grego no tocante à cosmologia, à psicologia, à gnosiologia, e mesmo desenvolvendo aspectos não explorados por Platão, o que, porém, não os impedia de complementar suas filosofias platônicas com dados de fé quando se viam diante da necessidade de tratar de temas como a origem temporal do mundo, o destino da alma após a morte etc. Vale a pena, aqui - sobretudo se se tem em vista o pouquíssimo conhecimento desse período por parte da comunidade filosófica brasileira -, evocar um trecho de extrema lucidez histórico-filosófica, encontrado no livro de Anca Vasiliu sobre a imagem (eikôn) nos três capadócios: "O contexto dos séculos III e IV é fundamental para compreender o que os termos imprecisos e controversos platonismo e filosofia designam na transmissão da herança clássica e para saber o papel específico de Platão na estruturação de uma primeira teologia cristã. Mas esse contexto, chamado comumente de Antiguidade Tardia, é também particularmente complexo porque ele conhece uma multiplicação de referências, de versões e de sínteses, ao mesmo tempo que vê surgirem mutações radicais nas opções religiosas e, portanto, nos paradigmas e princípios filosóficos e científicos. Ora, essa disseminação e essas mutações de referências não implicam, entretanto, uma renúncia a certo tipo de linguagem, certos hábitos de estratégia discursiva e certos métodos de análise, demonstração, exegese e comentário filosófico. O gosto pelos sabores da Retórica e o costume de utilizar a demonstração dialética em um discurso (mesmo se se tratasse frequentemente de textos escritos e destinados à leitura, e não à proclamação diante de um público) fazem ainda parte da instrução de base e carregam numerosos elementos do pensamento antigo que não apontam necessariamente para leituras precisas de autores nem para modelos ou correntes filosóficas, mas testemunham, acima de tudo, um estilo ou algo como uma forma de pensar. Esse estilo, essa forma de pensar, a preeminência intelectual da Escola dos Antigos e a expertise retórica que codifica a linguagem e 
domina todo ato de fala são a expressão da autoridade intelectual de que goza a herança antiga como modelo cultural, paidético, para além de toda opção doutrinal precisa, apesar da mudança fundamental de paradigma imposta pelo cristianismo. Sem dúvida, o 'platonismo' sobrevive graças a essa permanência do modelo formador antigo, mas ele recebe também um tratamento preferencial; mais do que todas as outras 'escolas', suas teses são captadas no seio do novo paradigma cultural que se impõe com o cristianismo hegemônico." ${ }^{2}$

Não deixa de ser em continuidade com essa temática - mas com uma considerável expansão de sua abrangência - que Anca Vasiliu trouxe a público seu último livro, em 2018, intitulado Pensar Deus - Noética e metafísica na Antiguidade Tardia. A estrutura do livro não é historicamente linear, embora parta do Timeu e de Metafísica $\Lambda$. Inicia realmente com Fílon de Alexandria, retorna a Platão e dele passa a Porfírio; chega a Mário Vitorino; retorna a Plotino e a Vitorino; retorna a Aristóteles e novamente a Plotino e Vitorino; faz novo recuo a Aristóteles; passa por Basílio de Cesareia e retorna a Vitorino; novamente volta a Plotino, Porfírio e Vitorino, avançando a Basílio e Boécio; por fim, retorna a Platão e dele remete ao Livro dos XXIV filósofos (texto anônimo de cuja existência o primeiro testemunho é dado no século XII e que recebeu este título de Mestre Eckhart). As idas e vindas entre os autores deixam claro que o objetivo de Anca Vasiliu não é traçar os contornos de uma história do tema do "pensar Deus", mas explorar as virtualidades desse tema, seguindo um fio que, ele mesmo, faz recuos e avanços, revelando a força de sua própria perspectiva como pensadora ancorada na tradição e não apenas como historiadora (seja da filosofia, seja das ideias em geral).

Se a redação de Anca Vasiliu, sobretudo especificamente nesta obra, revela já um cuidado agudo com o estilo e a perfomance sintática, a menção ao Livro dos XXIV filósofos (menção esta por ela chamada de "anacronismo idealmente pertinente") confirma sua preocupação em trazer à tona e explorar como pensadora de primeira grandeza o tema do pensar e falar de Deus, visualizando-o como um tema que não ganha inteligibilidade senão sob a perspectiva do todo-totalidade, do um-unidade e da distinção entre Deus e a Deidade. Para além do aspecto histórico que atestaria no "neoplatonismo" em geral e em Boécio fontes certeiras para o livro dos filósofos, o que é mais instigante é a continuidade do fio que, no limite, remonta a Platão, por um lado, e, por outro, confirma as virtualidades exploradas por Anca Vasiliu.

O segundo aforisma que retrata Deus no Livro dos XXIV filósofos é bastante sintomático: Deus é uma esfera sem limite cujo centro está por todo lado e cuja

${ }^{2}$ VASILIU, A. EIKÔN - L'image dans le discours des trois cappadociens. Paris: PUF, 2010, p. 42-43. 
circunferência não está em lugar nenhum. Mas é o nono aforisma que mais dá a pensar à autora: Deus é, para ele só, o presente de tudo o que pertence ao tempo (variante: Deus é aquele para quem é presente tudo o que pertence ao tempo). À luz desse aforisma pode-se ver com maior clareza o problema preciso de que trata o livro de Anca Vasiliu. Trata-se de investigar a possibilidade de pensar aquele ou aquilo que é considerado, por excelência, o impensável ou o não dominável conceitualmente. O problema não é novo, mas a abordagem da autora o é, a começar pela fuga da linearidade histórica e a ativação de possibilidades exegéticas antes insuspeitadas. Se se afirma ao mesmo tempo, por um lado, que Deus, o Uno, o Bem, escapa à dominação conceitual, e, por outro lado, que ele também é, e, mais do que isso, que ele a tudo determina, então se parece chegar a um impasse ou mesmo a uma contradição: é ou não é possível pensar Deus, o Uno, o Bem? Mais grave ainda: é possível pensar Deus como impensável?

Uma solução, de sabor crítico-moderno, estaria em remeter o vocábulo Deus a algo como um "referente" incondicionado, não "natural", e sim da ordem da transcendência de algo como "a coisa em si" de um idealismo de tipo kantiano. Nesse "objeto impossível" do pensamento encontrar-se-iam as mesmas qualidades essenciais da invariabilidade, do estatuto exclusivamente inteligível, da unicidade e da identidade autorreferente e autoidêntica, por oposição ao que é da ordem do indefinível porque aparente, fenomenal, sensível, mutável. Sob uma perspectiva como essa, "potencialidade e atualidade seriam, aliás, simultâneas, pois, como no caso de Deus, o pensamento pensa simultaneamente potencialidade absoluta e atualidade absoluta" (p. 23). Donde parecer desnecessário associar o termo Deus a algum referente como algo ou alguém que hipostatizaria uma transcendência propriamente divina, boa e una. Mas essa operação, como insiste Anca Vasiliu, não basta para reduzir Deus a uma ideia; afinal, a razão não somente não encontra Deus por essa operação, mas, além disso, ainda que pretenda circunscrever-se à sua própria preeminência, ela permanece, na realidade, fechada na aparente suficiência de sua própria circularidade. Se o pensamento é ele mesmo "divino", então pensar Deus significa pensar o pensamento em sua essência (como quididade)? Ou, ao contrário, a redução à ideia não passa de uma estratégia para evitar a "divinização" do intelecto e de sua inerente "substantivação" sob a hipóstase de um noûs essencialmente divino?

As raízes dessa problemática deixam-se encontrar, segundo Anca Vasiliu, já no Timeu, e vale aqui dar a palavra a ela própria, a fim de esclarecer a motivação que a levou a repropor tema tão antigo e tão novo: "Se se admite que o intelecto é 'divino' e que as ideias são os 'pensamentos de Deus', o ser humano pode exercer ainda sua faculdade intelectiva para pensar Deus? Ou, então, o pensamento, pensando-se a si mesmo, pensa necessariamente sua atualidade (ou seu ato) como única expressão do divino? $\mathrm{Ou}$, ainda, a possibilidade mesma de o pensamento pensar-se a 
si mesmo é a condição sine qua non do pensamento para pensar Deus? O pensamento pensa necessariamente uma 'ideia' de Deus apenas porque não pode pensar Deus senão pensando assim, quer dizer, de maneira autorreflexiva? Se o pensamento é realmente divino, não há nele uma 'ideia de Deus' (eidos theou), mas somente uma correspondência perfeita, e mesmo uma identidade absoluta entre 'pensar' e 'Deus'. Ou, então, não é por uma 'ideia de Deus' que o pensamento pensa Deus, mas por um meio de intelecção segundo: entendendo ideia seja como um modelo ( $p a-$ radeigma), seja por um conceito, uma imagem, uma representação (ennoia, phantasma, species). O pensamento evitaria, assim, atribuir ao incondicional a condição de uma forma subjacente à ideia. Mas ele não evitará, por isso, de fazer do incondicional uma coisa pensável, submetendo, portanto, Deus à condição de um 'objeto' ad hoc do pensamento (noção operatória, argumento, prova, representação)." (p. 24).

Esse é o núcleo da inspiração que fará Anca Vasiliu reativar e reexplorar o pensar Deus e o indissociável falar de Deus. Infelizmente, nos limites de uma breve resenha, não é possível retratar sequer minimamente a riqueza de erudição e a fineza de análise contidas no livro. Resta, porém, manifestar a esperança de que ele seja traduzido em nossa língua, a fim de beneficiar os que não têm acesso ao original em francês. De todo modo, trata-se de um trabalho de cuja leitura sai-se não apenas enriquecido, mas com uma admirável ampliação de horizontes teóricos. 